\title{
Prevalence of anaemia among the male population aged 60 years and above in rural area of Paschim Medinipur, West Bengal, India
}

\author{
S Maiti ${ }^{1,3}$, A Ghosh ${ }^{1}, \mathrm{KM} \mathrm{Ali}^{1}$, K Jana ${ }^{1}$, D Ghosh ${ }^{1,2,3}$ S Paul $^{2,3}$ \\ ${ }^{1}$ Departent of Bio-Medical Laboratory Science \& Management, Vidyasagar University, West Bengal, \\ India, ${ }^{2}$ Nutrition \& Dietetics Unit, Dept. of Bio-Medical Laboratory Science \& Management, Vidyasagar \\ University, West Bengal, India, ${ }^{3}$ Rural Research Institute of Physiology \& Applied Nutrition (RRIPAN), \\ West Bengal, India
}

\begin{abstract}
Background: Anaemia is one of the most common public health problems of older population especially in developing countries. Objective: To determine the prevalence and type of anaemia present among the older people in rural area of Paschim Medinipur, West Bengal. Methods: A cross-sectional study was undertaken on 544 older male, Subject aged 60 to 84 years from Paschim Medinipur, West Bengal. Personal details were collected in each case, after which height, weight, body mass index (BMI) and blood haemoglobin level were measured according to the standard protocol. Anaemia was classified as per the World Health Organisation (WHO) grading criteria. Results: The overall prevalence of anaemia among the older male was $89.52 \%$. The majority (256) (47.05\%) showed mild anaemia, while moderate anaemia was recorded in 212 (38.97\%) and 19 (3.49\%) subjects, had severe anaemia. The prevalence of anaemia was more (65.62\%) in individuals, having low BMI than normal. Conclusion: The results showed high frequency of anemia in the studied population. There is a need for immediate nutritional intervention programs to be implemented among the rural older male subjects.
\end{abstract}

Keywords: anaemia, CED, BMI, haemoglobin

\author{
Introduction \\ On the basis of global scenario, in 2000 there were \\ 600 million people aged 60 or over, and it is estimated \\ that this figure will double by 2025, and more than \\ triple to 2 billion by $2050 .{ }^{1}$ Smith $(2000)^{2}$ found the \\ prevalence of anaemia to increase sharply after the \\ age of 60 years. So, it is important to find out and \\ understand the significance of common medical \\ problems in older people. Anemia may be one such \\ problem. The problem is much more in rural than \\ the urban areas. ${ }^{3}$ \\ Address for correspondence \\ Dr Shyamapada Paul \\ Director, Rural Research Institute of Physiology \& Applied \\ Nutrition (RRIPAN) \\ 'Gitanjali', Dr. Nilay Paul Road, Midnapore - 721 101, \\ West Bengal, India \\ Email: paul_shyamapada@rediffmailcom
}

Anemia is defined as a condition characterized by reduction of the concentration of hemoglobin in blood below the normal level. It is the common hematological abnormalities in older population and its prevalence arises with the advancement of age. According to the World Health Organization (WHO), anemia (hemoglobin level less than 13 g per dL [130 g per L] in men and less than $12 \mathrm{~g}$ per dL [120 g per L] in women), a large study found that the corrected annual incidence of anemia increased steadily with advancement of age. In general, the level of hemoglobin is found to be lowering in older than young people. The exact causes behind this are not cleared. It is unclear whether hemoglobin falls in older people because this is a feature of normal ageing, or whether it is always pathological, even if underlying conditions 
cannot be identified. In an individual patient it may be that some decline in hemoglobin occurs as part of normal ageing, but that disease may also contribute to the development of anemia. ${ }^{4}$

The prevalence of anemia in elderly individuals aged 65 years or older is around $10 \%$ and increases with age to above $20 \%$ in subjects aged 85 years or older. ${ }^{5,6}$ From 65 to 69 years of age, the incidence of new-onset anemia was 6 percent in men and 4 percent in women. In persons 85 years and older, the annual incidence rose to 14 percent in men and 13 percent in women. ${ }^{7}$ Multiple studies demonstrate that anemia is an independent risk factor for increased morbidity and mortality, and decreased quality of life in community-dwelling older persons. ${ }^{8}$ So, study of anemia among the older people in the different zone of our country is required in connection with to find out the epidemiological scenario of this disorder. In this respect, this study was undertaken to determine the prevalence and main types of anemia present among older people in rural area of Paschim Medinipur, West Bengal. This report is to the best of our knowledge, the first study of anemia among older people in rural area of West Bengal, India

\section{Methods \\ Study population}

Cross sectional community based study was carried out in the month of September, 2010 in rural area of 11 blocks, Sankrile, Gopi-I, Gopi-II, Nayagram, Binpur-I, Binpur-II, Jamboni, Midnapore Sadar, Salboni, Garbeta-II in Paschim Medinipur district, West Bengal, India. The relevant data were collected from target population belong to low socio economic group. Older male subjects were visited (at ages 6084 years) at their place of residence to participate in this study and the total sample size is 544 . The geographical location is latitude $22^{\circ} 70^{\prime}$ north and longitude $86^{\circ} 59^{\prime}$ east. This area has uniqueness in terms of demographic and socioeconomic characteristics.

\section{Hematological assessment}

Capillary blood was collected from each participant using a finger-prick method to extract three drops of blood from the left middle finger. The first and second drops of blood were wiped away. The third drop was used immediately for testing Hemoglobin level. The measurement of hemoglobin level was conducted by using a Hemocue $\mathrm{Hb}$ analyser.

\section{Anthropometric study}

Height and weight of each subject were measured using standard protocol as recommended by WHO. ${ }^{9}$ Height and weight were recorded up to the nearest $0.1 \mathrm{~cm}$ and $0.5 \mathrm{~kg}$, respectively. BMI was computed by the following standard equation.

BMI = weight $(\mathrm{kg}) /$ height $\left(\mathrm{m}^{2}\right)$.

Nutritional status was evaluated based on BMI guidelines of WHO (1995).

The different cut-off points were used here as follows: Chronic energy deficiency when BMI $=<18.5$

Normal when BMI $=18.5-24.9$

Overweight when BMI $=\geq 25.0$.

\section{Assessment of anaemia}

Anaemia was categorized according to the hemoglobin levels in to mild (10.0-10.9 $\mathrm{g} / \mathrm{dl})$, moderate (8.0-9.9 g/dl) and severe $(<8.0 \mathrm{~g} / \mathrm{dl})$.

\section{Ethical consideration}

Ethical permission was obtained from Vidyasagar University and local community leaders, respectively, before commencement of the study. The study protocol was fully explained to the subjects and consent was obtained prior the commencement of the study.

\section{Results}

There are 544 older male in rural population participating in this study having age group 60-84 years. Age group wise anthropometric variable along with blood hemoglobin level of participants are depicted in Table 1. The overall height, weight and BMI were $166.55 \mathrm{~cm}, 43.65 \mathrm{~kg}$ and $16.90 \mathrm{~kg} / \mathrm{m}^{2}{ }^{2}$ BMI was increased up to age group of 65-69 years with the advancement of age. But hemoglobin levels were decreased with the advancement of age. Mean blood haemoglobin level was $9.96 \mathrm{~g} / \mathrm{dl}$. 
Table 1: Age group wise mean height, weight, BMI and haemoglobin among rural older male

\begin{tabular}{|l|l|l|l|l|l|}
\hline $\begin{array}{l}\text { Age Groups } \\
\text { (in years) }\end{array}$ & No. & $\begin{array}{l}\text { Height } \mathbf{( c m )} \\
\text { Mean } \pm \text { SD }\end{array}$ & $\begin{array}{l}\text { Weight (kg) } \\
\text { Mean } \pm \text { SD }\end{array}$ & $\begin{array}{l}\text { BMI (kg/m } \\
\text { Mean } \pm \text { SD }\end{array}$ & Hb (g/dl) \\
\hline $60-64$ & 141 & $161.12 \pm 6.26$ & $44.87 \pm 7.68$ & $17.27 \pm 2.69$ & $10.19 \pm 0.887$ \\
$65-69$ & 136 & $160.72 \pm 7.06$ & $45.46 \pm 8.73$ & $17.53 \pm 2.73$ & $10.15 \pm 0.69$ \\
$70-74$ & 152 & $160.10 \pm 5.99$ & $41.73 \pm 7.68$ & $16.27 \pm 2.80$ & $9.71 \pm 0.87$ \\
$75-79$ & 65 & $159.61 \pm 5.87$ & $42.25 \pm 6.45$ & $16.57 \pm 2.39$ & $9.63 \pm 0.88$ \\
$80-84$ & 50 & $161.05 \pm 5.31$ & $42.94 \pm 8.32$ & $16.50 \pm 2.67$ & $9.54 \pm 1.01$ \\
\hline Overall & 544 & $160.55 \pm 6.3$ & $43.65 \pm 8.04$ & $16.90 \pm 2.74$ & $9.96 \pm 0.88$ \\
\hline
\end{tabular}

Table 2 showed age group wise prevalence of anaemia and their different grads. The overall prevalence of anaemia was $89.52 \%$ where as 47.05\%, 38.97\%, 3.49\% belongs to mild, moderate and severe groups of anaemia respectively. The heights frequency (98.02\%) of anaemia observed among the age group 70-74 years whereas age group of 60-64 years indicates lowest frequency. Only $10.47 \%$ of older male in present study area fall in normal.

Table 2: Age group wise prevalence of anaemia among rural older male

\begin{tabular}{|l|r|r|r|r|r|r|}
\hline Characteristic & \multirow{2}{*}{ No. } & \multicolumn{4}{|c|}{ Status of anaemia } & \multirow{2}{*}{ Normal } \\
\cline { 3 - 6 } & & Mild & Moderate & Severe & Total & \\
\hline $60-64$ & 141 & $73(51.77)$ & $44(31.20)$ & $2(1.41)$ & $119(84.39)$ & $22(15.60)$ \\
$65-69$ & 136 & $66(48.52)$ & $50(36.76)$ & $1(0.735)$ & $117(86.02)$ & $19(13.97)$ \\
$70-74$ & 152 & $72(47.36)$ & $69(45.39)$ & $8(5.26)$ & $149(98.02)$ & $3(1.97)$ \\
$75-79$ & 65 & $27(41.53)$ & $26(40)$ & $3(4.61)$ & $56(86.15)$ & $9(13.84)$ \\
$80-84$ & 50 & $18(36)$ & $23(46)$ & $5(10)$ & $46(92)$ & $4(8)$ \\
Overall & 544 & $256(47.05)$ & $212(38.97)$ & $19(3.49)$ & $487(89.52)$ & $57(10.47)$ \\
\hline
\end{tabular}

The weighted percentage along with different categories of anaemia by body mass index is presented in Table 3. It indicates in case of low BMI (less than $18.5 \mathrm{~kg} / \mathrm{m}^{2}$ ), $65.62 \%$ of subjects were found to be anaemic than those subjects with normal BMI between 18.5 and $24.9 \mathrm{~kg} / \mathrm{m}^{2}$ (22.42\%). Whereas chance of anaemia is much more less in case of over-weight subjects $(1.47 \%)$ who fall in category of high BMI $\left(\geq 25 \mathrm{~kg} / \mathrm{m}^{2}\right)$.

Table 3: Weighted percentages of older male with different grades of anaemia by body mass index

\begin{tabular}{|c|c|c|c|c|c|c|}
\hline \multirow[t]{2}{*}{ BMI $\left(\mathrm{kg} / \mathrm{m}^{2}\right)$} & \multicolumn{4}{|c|}{ Status of anaemia } & \multirow[t]{2}{*}{ Normal } & \multirow[t]{2}{*}{ Overall } \\
\hline & Mild & Moderate & Severe & Total & & \\
\hline$<18.5$ & $179(45.54)$ & $162(41.22)$ & $16(4.07)$ & $357(65.62)$ & $36(9.16)$ & $393(72.24)$ \\
\hline $18.5-24.9$ & $71(50)$ & $48(33.80)$ & $3(2.11)$ & $122(22.42)$ & $20(14.08)$ & $142(26.10)$ \\
\hline$\geq 25$ & $5(55.55)$ & $3(33.33)$ & - & 8 (1.47) & 1 (11.11) & $9(1.65)$ \\
\hline Total & $255(46.87)$ & $213(39.15)$ & 19 (3.49) & 487 (89.52) & $57(10.47)$ & $544(100 \%)$ \\
\hline
\end{tabular}

\section{Discussion}

Anaemia continues to be a major public health problem at all ages worldwide. It is common in older adults and is an independent predictor for increased morbidity and mortality in several disease states. ${ }^{10}$ We conducted a community based study to determine the prevalence of anaemia among older male. 
In the present study, BMI levels were increased up to age groups of 65-69 years than decline whereas mean blood $\mathrm{Hb}$ level showed a decline with advancing of age. Present study showed $46.87 \%$ subjects were mild anaenic, $39.15 \%$ were moderate anaemic and $3.49 \%$ were severe anamic whereas $10.47 \%$ subjects had normal. According to WHO if the prevalence of anemia at community levels is more than $40 \%$, it is considered as problem of high magnitude. ${ }^{3}$

Another study carried out in the southern part of India reported a much higher prevalence of anaemia $(82.9 \%)$ in the 60 years and above age group. ${ }^{11}$ But the study showed higher prevalence of anaemia (89.52\%) than earlier study. This difference may be explained by the structure of the geographical and socio-economical variation and it is the fact that the prevalence of anaemia is high in the eastern zone of India. ${ }^{12}$ The present study area is one of the poorest areas. In this area lack of required food is one of cause of anemia.

This study focussed that the prevalence of anaemia was more (65.62\%) in individual having low BMI than normal. One of the previous studies has shown a significant association of anaemia was seen with low BMI, this study also supports our findings. ${ }^{13}$

The study had some limitations. The causes of anaemia were not properly identified. It might be mostly due to chronic disease and insufficient micronutrient intakes such as iron, vitamin B12 and/ or folate. For the future work, nutritional status of micronutrients must be evaluated either by dietary and biochemical analyses and strategies to improve the nutritional and health status of the rural older population must be developed.

\section{Conclusion}

Anaemia in older male subjects is a severe public helath problem in underprivileged areas of West Bengal. There is a need for immediate nutritional intervention program to be implemented among the rural older male.

\section{Acknowledgements}

We are grateful to the Indian Red Cross Society Paschim Medinipur district branch for conducting this work. Finally, we wish to thank the people of study area for their extensive co-operation with this survey.

\section{References}

1. World Health Organization, ageing and life course [http:// www.who.int/ageing/en]

2. Smith DL. Anaemia in the elderly. Am Fam Physician 2000; 62: 1565-72.

3. Seshadri S. A database on iron deficiency anaemia (IDA) in India: prevalence, causes, consequences and strategies for prevention. Department of Foods and Nutrition. WHO Collaborating Centre for Nutrition Research. The Maharaja Sayajirao University of Baroda, Vadodara, India, 1999.

4. Helen Gaskell, Sheena Derry, R Andrew Moore and Henry J McQuay. Prevalence of anaemia in older persons: systematic review. BMC Geriatrics 2008; 8:1.

5. Beghe C, Wilson A, Ershler WB. Prevalence and outcomes of anaemia in geriatrics. Am J Med 2004; 116:3S-10S.

6. Guralnik JM, Eisenstaedt RS, Ferrucci L, Klein HG, Woodman RC. Prevalence of anaemia in persons 65 years and older in the United States: evidence for a high rate of unexplained anaemia. Blood 2004; 104(8):2263-68.

7. Anía BJ, Suman VJ, Fairbanks VF, Rademacher DM, Melton LJ III. Incidence of anaemia in older people: an epidemiologic study in a well defined population. JAm Geriatr Soc 1997; 45(7):825-31.

8. Chaves PH, Ashar B, Guralnik JM, Fried LP. Looking at the relationship between hemoglobin concentration and prevalent mobility difficulty in older women. Should the criteria currently used to define anaemia in older people be reevaluated? J Am Geriatr Soc 2002; 50(7):1527-64.

9. World Health Organization. Physical status: The use of interpretation of anthropometry. Technical report series. Geneva, WHO; 1995. Report No.: 854.

10. Woodman R, Ferrucci L, Guralnik J. Anaemia in older adults. Curr Opin Hematol 2005; 12: 123-28.

11. Niranjan GV, Vasundhra MK. A study of health status of aged persons in slums of urban field practice area, Bangalore. Indian J Com Med 1996;21:1-4.

12. Ghosh S. Exploring socioeconomic vulnerability of anaemia among in Eastern Indian states. Journal of Biosocial Science 2009; 41:763-87.

13. Ahmad N, Kalakoti P, Bano R, Aarif SSM. The prevalence of anaemia and associated factors in pregnant women in a rural Indian community. Austr Med J 2010; 3(5):276-80. 